\title{
Poder y política en la era absolutista medieval del renacimiento
}

\author{
Beverly Estela Castillo Herrera ${ }^{1}$
}

1 Beverly Castillo Herrera, estudiante del doctorado en Ciencias Sociales con mención en Gerencia de la Universidad del Zulia, Venezuela. Docente de la Universidad Nacional Autónoma de Nicaragua (UNANManagua), Facultad Regional Multidisciplinaria de Estelí (FAREM-Estelí). E-mail: beverly.castillo@yahoo.com

\section{RESUMEN.}

La era absolutista medieval abarca los siglos XVI al XVIII, este período define el inicio de la era moderna porque aquí se sientan las bases filosóficas y teóricas que niegan el feudalismo medieval para dar paso al estado absolutista, donde el rey ejerce el poder absoluto. En esta época se desarrolla el renacimiento que representa un amplio movimiento cultural donde se producen cambios significativos en las artes, las ciencias, la política, la filosofía y la religión. El enfoque central del renacimiento está en el ser humano como centro del pensamiento occidental, se desarrolla el humanismo medieval, donde se combina el racionalismo y el naturalismo. En este artículo se anotan los principales aportes de: Nicolás Maquiavelo, Jean Bodin, Thomas Hobbes, John Locke, Erasmo de Róterdam, Tomás Moro y los iluministas franceses del Siglo XVIII Montesquieu, Voltaire y Rousseau. La base metodológica de este artículo es la investigación documental bibliográfica y en línea.

Palabras Clave: Poder, política, estado absolutista, renacimiento. 


\title{
Power and Politics in the Medieval Absolutism of the Renaissance
}

\author{
Beverly Estela Castillo Herrera ${ }^{1}$
}

1 Beverly Castillo Herrera, PhD student in Social Sciences with a major in Management from the University of Zulia, Venezuela. Teaching from Nacional Autónoma de Nicaragua (UNAN-Managua), Facultad Regional Multidisciplinaria de Estelí (FAREM-Estelí). E-mail: beverly.castillo@yahoo.com

\begin{abstract}
.
Absolutism (XVI - XVIII centuries) marks the start of the modern era because it lays the philosophical and theoretical bases that refuse the medieval feudalism and gave way to the absolutist state, where the king had absolute power. Renaissance arises in this period; it represents a broad cultural movement where significant changes in the arts, sciences, politics, philosophy and religion take place. The central focus during the Renaissance is the human being as the center of Western thinking and medieval humanism is developed, which combines rationalism and naturalism. This article highlights the main contributions of: Niccolo Machiavelli, Jean Bodin, Thomas Hobbes, John Locke, Desiderius Erasmus, Thomas More and three important scholars of the French Enlightenment (XVIII) Montesquieu, Voltaire and Rousseau. The methodological basis of this article is bibliographic and documentary research online.
\end{abstract}

Keywords: Power, politics, absolutism, state, renaissance. 


\section{INTRODUCCIÓN}

La era absolutista medieval del renacimiento abarca los Siglos XV al XVIII, se le conoce como el inicio de la edad moderna porque en esta época se presentan eventos históricos que provocan grandes cambios, se desarrolla el estado absolutista, y se da el renacimiento de la humanidad en las artes, la ciencia y la filosofía. Ávila y Guillezeau (2009) afirman que la complejidad y multidimensionalidad de la filosofía política del renacimiento sucede porque sus teorías políticas provienen de la formación de monarquías nacionales y absolutas, así como de las ideas provenientes de la reforma.

La base metodológica de este artículo es la investigación documental bibliográfica y en línea. Este artículo se organiza en tres partes. La primera parte pretende contestar la pregunta: ¿Cuál es la premisa teórica y política sobre la que se sustenta el estado absolutista?, se abordan los aportes sobre el Derecho Divino de los Reyes que desarrollan Bodino, Hobbes, Bossuets y Jacobo I. La segunda parte trata sobre el mercantilismo, que se concibe como la base del poder económico del estado absolutista, aunque son básicamente medidas económicas que están enfocadas en la acumulación del oro y la plata, y el incremento de las exportaciones. Finalmente, se aborda el humanismo renacentista, que está comprometido con la renovación del individuo, valorar el mundo humano, su origen y libertad para decidir y opinar.

\section{DESARROLLO}

\section{El derecho divino de los reyes, premisa del estado absolutista}

El absolutismo se establece en Europa en el siglo $\mathrm{XVI}$ cuando se produce una rápida expansión de las actividades, recursos económicos y poder interno de los reyes de los estados absolutos. En todo estado absolutista el poder está concentrado en el rey con su corona. El absolutismo es una doctrina política que afirma que el rey es el único que crea leyes y ejerce el poder sin restricciones porque le viene de Dios. Esta es la doctrina política que predominó en este siglo en tres grandes países absolutistas: La dinastía de Los Tudor en Inglaterra, Enrique XIV en Francia y en España con Carlos I y su hijo Felipe II. Un aspecto en común de estas monarquías fue la tradición como sustento de autoridad.

Según Anderson (1989): "En el transcurso del siglo XVI apareció en Occidente el Estado absolutista. Las monarquías centralizadas de Francia, Inglaterra y España representaron una ruptura decisiva con la soberanía piramidal y fragmentada de las formaciones sociales medievales, con sus sistemas de feudos y estamentos" (p.9). “...la llegada del absolutismo nunca fue, para la propia clase dominante, un suave proceso de evolución, sino que estuvo marcada por rupturas y conflictos extremadamente duros en el seno de la aristocracia feudal, a cuyos intereses colectivos en último término servía". (p. 137)

Uno de los principales defensores del estado absolutista fue Nicolás Maquiavelo (1469-1527). En 1513 escribe El Príncipe y en 1531 publica los Discursos sobre los diez primeros libros de Tito Livio, estas son las dos obras fundamentales que definen su pensamiento político. En la obra El Príncipe se realiza un análisis de los diferentes tipos de gobierno de su época, traza los rasgos del gobernante y los métodos que debe seguir para mantener el poder.

Para Maquiavelo el poder es la capacidad de obligar a otros a la obediencia. En el ejercicio del poder rechaza cualquier norma ética o moral en favor de la razón de Estado y la eficacia. Todo es válido en la práctica del poder porque la anarquía es el peor de los males, y un príncipe es preferible a la anarquía. Por ello, considera que un país es afortunado cuando tiene leyes que lo sostienen y a las que todos están sometidos, es el Estado de Derecho. 
Sin embargo, el príncipe está por encima de la ley y la moral del pueblo, debe ser ante todo un gran organizador, un individuo que prevé todas las posibles consecuencias de los que se propone y debe saber actuar con astucia. El príncipe es un hombre que sabe actuar en el terreno práctico, solo de esta manera puede lograr el Bien del pueblo, el Bien Común, que lo mantendrá en el Poder.

Avila y Guillezeau (2009) consideran que Maquiavelo es el iniciador del pensamiento político laico al elaborar el realismo donde se plantea como única base que la verdad es refutable y puede ser desmentida al surgir nuevos hechos, alejándose de las utopías estériles. Estos autores afirman que por ello "Se concibe a Maquiavelo como el autor de la teoría de la "virtud" republicana, entendiendo por tal la capacidad política para comprender la realidad de una manera objetiva y la conduce hacia lo que se pretende hacer" (p.156)

Otros teóricos del estado absolutista que sientan la base del Derecho Divino de los Reyes fueron: Jean Bodino (1530-1596), el filósofo Thomas Hobbes (1588-1679), Jacques Bossuets (1627-1704) y el rey Jacobo I Estuardo.

JeanBodin(1530 - 1596) consideradoel gran intelectual del Siglo XVI, publica en 1576 su obra más importante Les six livres de la République. Según Fazzio (2006) Bodin intenta dar un fundamento sólido al poder real a través de una doctrina sobre la soberanía. Señala que existe un Estado ahí donde los ciudadanos están sujetos a la ley de un soberano común. La soberanía es un poder perpetuo, no limitado en el tiempo, no delegado, inalienable, no sujeto a prescripción, ni limitado por las leyes, ya que el soberano es él mismo la fuente de la ley. Para Bodin las prerrogativas de la soberanía son el poder dictar leyes sin necesidad de ningún consentimiento ajeno; declarar la guerra y la paz; instituir los principales funcionarios del estado; juzgar en calidad de corte inapelable; conceder gracias; acuñar moneda e imponer impuestos (p. 5758)
En la teoría absoluta de Bodin, la soberanía tiene algunas restricciones, “...los príncipes de la tierra están sujetos a las leyes de Dios y de la naturaleza y a ciertas leyes comunes a todos los pueblos... tampoco podrá tomar los bienes ajenos sin causa justa y razonable, es decir, por compra, trueque o confiscación legítima, o bien para hacer la paz con el enemigo, cuando ésta solo puede lograse de este modo"1

El rey Jacobo I Estuardo defiende la doctrina del Derecho Divino en su obra "La Verdadera Ley de las Monarquías Libres" (1598) donde considera al rey como el terrateniente de Dios.

Tomas Hobbes (1588-1679) es el teórico que elabora una justificación racional del Estado Absoluto, es considerado el primer pensador moderno que explica el ius naturalismo moderno desde parámetros racionales. Hobes en su obra Leviatán (1651) plantea que las naciones prosperan bajo una Monarquía porque tienen un príncipe al que le obedecen. Afirma que todos los hombres son iguales y tienen los mismos fines, pero que al buscarlos simultáneamente se convierten en enemigos implacables. En consecuencia para poder llevar una vida en sociedad debían ceder parte de sus derechos al Estado, para ello es necesario tener un poder fuerte concentrado en la figura real, quien así acumulaba todos los derechos a los que el hombre había renunciado.

Hobbes (1651) en el Leviatán expresa: "El único camino para erigir semejante poder común, capaz de defenderlos contra la invasión de los extranjeros y contra las injurias ajenas, asegurándoles de tal suerte que por su propia actividad y por los frutos de la tierra puedan nutrirse a sí mismos y vivir satisfechos, es conferir todo su poder y fortaleza a un hombre o a una asamblea de hombres, todos los cuales, por pluralidad de votos, puedan reducir sus voluntades a

1 Bodin, Jean (sf). Los seis libros de la república. Selección, estudio preliminar y traducción de Pedro Bravo Gala. Editorial TECNOS. Tercera edición. Pag.53 y 64. 
una sola voluntad (...) la multitud así unida en una persona se denomina ESTADO, en latín, civitas. Esta es la generación de aquel gran LEVIATAN, o más bien (hablando con más reverencia), de aquel dios mortal, al cual debemos, bajo el Dios inmortal, nuestra paz y nuestra defensa (...) El titular de esta persona se denomina SOBERANO, y se dice que tiene poder soberano; cada uno de los que le rodean es SÚBDITO suyo". (p.11)

Jacques Bossuet (1627-1704), en su obra "Política sacada de las Sagradas Escrituras" basa su reflexión en la Biblia y el Derecho Romano, afirma que el rey representa a la Majestad divina: "El trono regio no es el trono de un hombre, sino el del mismo Dios". Bossuet consideraba que la monarquía era la forma de gobierno más natural, sobre todo si es hereditaria. Era "sagrada" y absoluta.

Los planteamientos anteriores sobre el poder absoluto del monarca como reflejo del poder divino se concreta en la forma de administrar justicia, crear leyes, imponer penas, nombrar magistrados, dirigir la política exterior, y ser comandante de los ejércitos, no se sometía a ningún control, ni compartía la soberanía con nadie. El poder del rey era vitalicio, al morir el poder pasaba a su hijo. Un ejemplo sobre el poder absoluto de los reyes lo refleja el Rey de Francia Luis XIV en su conocida frase: "El estado soy yo".

Anderson (1987) afirma que las monarquías absolutas de Occidente se asentaron en un cualificado estrato de legistas que proveían de personal a sus maquinarias administrativas: los letrados en España, los maitres des requetés en Francia, los doctores en Alemania. Imbuidos en las doctrinas romanas de la autoridad del príncipe para decretar y en las concepciones romanas de las normas legales unitarias, estos burocráticasjuristas fueron los celosos defensores del centralismo real en el crítico primer siglo de la construcción del Estado absolutista (p.141)
Para ejercer el poder, el monarca estaba auxiliado por instituciones que lo asesoraban y ejecutaban sus mandatos. El principal órgano de gobierno era el Consejo de Estado, designados por el rey, existían subdivisiones especializadas como: Consejos de Finanzas, de Justicia, de Guerra, entre otros. También se designaron a Secretarios de Estado, comparables a los actuales ministros.

El modo de integración de la nobleza feudal en el Estado Absolutista que prevaleció en Occidente adoptó la forma de adquisición de "cargos". También el estado siempre carente de suficientes recursos y muchas necesidades, pone en venta los empleos, los burgueses y los particulares que compraban privadamente una posición la amortizaba mediante la corrupción y prebendas que implica un cargo público, incluso exigen el derecho de revender o ceder el cargo a hijos y familiares. De esta manera se forma una clase de empleados.

Romano y Tenenti (1986) explican: “... el funcionario que entra en el mecanismo del estado se adueña del poder, y comienza a constituir una clase en sí mismo, la cual descubre que está, demasiado a menudo, mal retribuida en relación con el poder y con las funciones que ejerce: de ahí la corrupción burocrática". (p. 271)

En el estado absolutista existió una sociedad estamental dividida en tres estamentos: nobleza, clero y tercer estado. Cada uno de ellos presenta desigualdades jurídicas y fiscales. Mientras la nobleza y el clero se consideraban estamentos privilegiados, el tercer estado era el estamento no privilegiado, donde se ubicaba la mayoría de la población. Esto demuestra una sociedad muy desigual.

La nobleza se trataba de un grupo cerrado, al que teóricamente se tenía acceso por nacimiento, aunque en el siglo XVIII muchos burgueses enriquecidos compraban títulos nobiliarios. Pero, también existían diferencias entre alta y baja nobleza, según sus 
títulos, privilegios, extensión de propiedades y cargos en la corte. El clero en el estado absolutista tenía una gran influencia cultural y política, tenía propiedades y privilegios fiscales. También existía un alto clero, procedente de las familias nobles y un bajo clero: sacerdotes y frailes.

El tercer estado, integrado por quienes no formaban parte ni de la nobleza, ni del clero. Estaba integrado por burgueses, campesinos, artesanos y trabajadores urbanos. La gran mayoría no poseían tierra, recursos escasos y aún dependían de los señores, aunque esto fue cambiando en el siglo XVIII.

Anderson (1989) afirma que no solamente el comercio y la guerra fueron las únicas actividades externas del estado, otro gran esfuerzo se dirigió a la diplomacia, que se constituye en uno de los grandes inventos institucionales de la época, marcando el nacimiento del Estado Renacentista. La diplomacia se inauguró en Italia en el Siglo XV y adoptada en España, Francia, Inglaterra, Alemania y toda Europa en el Siglo XVI.

Con la diplomacia se establecieron embajadas en el extranjero y se nombraron cancilleres permanentes encargados de las relaciones exteriores, comunicaciones e informes diplomáticos secretos, protegidos por el nuevo concepto de "extraterritorialidad". Este concepto está relacionado con la propiedad de edificios o tierras que aunque estén ubicados en otro país se consideran que pertenecen al otro, como ocurre con embajadas y bases militares. Igualmente se aplica a la posibilidad de aplicar una ley fuera de los límites del territorio donde fue promulgada.

En el Siglo XVI los principales críticos del absolutismo fueron: el Jesuita Juan de Mariana (1536-1624) y Jhon Loke (1632-1704). Juan De Mariana (1536 - 1624), aunque era defensor del absolutismo, en su obra Tratado y discurso sobre la moneda de vellón que al presente se labra en Castilla y de algunos desórdenes y abusos (1609), sostenía que el rey recibía el poder de Dios a través del pueblo, donde el rey solo era el administrador de ese poder, pero si lo ejercía sin respetar la ley de Dios podía ser ajusticiado. Esta obra se hizo famosa sobre todo por la defensa del tiranicidio.

John Loke (1632 - 1704), en su doctrina del estado de naturaleza coincide con Hobbes, en cuando al punto de partida y a la realización del contrato; después, sus criterios se oponen en las conclusiones (Fabal, 1973). Locke consideraba que el gobierno debía de estar limitado por reglas que le prohibieran afectar los derechos a la propiedad y a la libertad individual. Por ello, defendió un sistema de control y la división de poderes.

Así mismo, en su obra: Dos tratados sobre el gobierno civil (1690), afirmó que la soberanía no reside en el Estado sino en el pueblo, por tanto existía el derecho a deponer al monarca cuando no cumpla el mandato de servicio a la colectividad que se le ha conferido e incluso tiene facultad de modificar el sistema político, adoptando cualquier otra forma de gobierno. También era partidario de la libertad religiosa y de la separación de la Iglesia y el Estado.

\section{El mercantilismo, la política económica de los estados absolutistas}

El poder del estado absolutista o nacionales también se refleja a nivel económico, el mercantilismo representa su política económica, comienza a implementarse a mediados de Siglo XV contra la anarquía económica del deteriorado medioevo y declina a mediados del siglo XVIII con la escuela liberal inglesa y a las doctrinas fisiocráticas en Francia.

El mercantilismo es la negación de las formas económicas medievales, permite sentar las bases para el desarrollo mercantil y manufacturero, es la doctrina económica de la nueva clase social que se 
ha venido formando en las ciudades. Sin embargo, quienes desarrollan este enfoque son personas que expresaron sus puntos de vista sobre el manejo de la economía de sus países, la mayoría no eran universitarios, ni cultos, pero ejercían actividades económicas como: banqueros, funcionarios y comerciantes que enfocaron su principal preocupación en "enriquecer a la nación".

Fabal (1973) considera: "Esta doctrina sirvió como programa económico para sentar las bases de su desarrollo mercantil y manufacturero (...) El mercantilismo es más un repertorio de medidas prácticas, de regulaciones y de propósitos, que un cuerpo de doctrinas; incluso apenas exhibe teóricos de relieve como John Child y Tomás Mun en Inglaterra". (p.104)

El término Mercantilismo fue acuñado en 1763 por Víctor de Riqueti, marqués de Mirabeau. En 1776, Adam Smith en su libro "La riqueza de las naciones", reúne la mayoría de las contribuciones del mercantilismo y denomina a este grupo de personajes "mercantilistas" y son conocidos como grupo a raíz de sus fuertes críticas.

En el libro cuarto (de los sistemas de economía política), capítulo primero (del principio del sistema mercantil), resumió lo central de las ideas mercantilistas (Citado por Borgucci, 2011, p. 364): “En el supuesto, pues, de que se establezcan como ciertos los dos principios: que la riqueza consiste en el oro y la plata, y que estos metales pueden introducirse en los países desprovistos de minas por el único medio de la balanza de comercio, o extrayendo mayor valor del que se introduce, el gran objetivo de la economía política habrá de ser disminuir todo lo posible la importación de géneros extranjeros para el consumo doméstico y aumentar, en lo posible, la exportación del producto de la industria nacional. Los dos grandes arbitrios para enriquecer un país no podían ser otros que las restricciones a la importación y el fomento de las exportaciones" (1982 [1776]:397).
Las principales medidas económicas que se impulsaron en los estados absolutistas en el marco del mercantilismo abarcan (Fabal, 1973):

- En lo aduanal, el proteccionismo arancelario.

- En lo comercial, la balanza de pagos favorable para promover más exportaciones (fomento industrial para exportación y subvención de la agricultura para abastecer el mercado interno) y reducir las importaciones (restricciones al comercio importador y regulaciones marítimas restrictivas).

- En lo colonial, la colonización y población de nuevos territorios y la expansión colonial que garantiza áreas inclusivas de exportación a la metrópoli.

- La explotación de minas por el estado.

Estas medidas beneficiaron tanto al último estado feudal como a la primera burguesía, en el primer caso se incrementaron sus ingresos fiscales y al segundo le proporcionó oportunidades de negocio que trascendieron de Europa hacia América.

El papel asignado a las colonias era de fuentes de ingreso y proveedoras de la materia prima necesaria para desarrollar la industria de la metrópoli. En América la corona Española controlaba los pueblos nativos para extraer el oro y la plata. Las principales actividades económicas que se desarrollaron en las colonias eran: la agricultura, comercio y minería.

\section{El humanismo renacentista}

Durante el período del estado absolutista también se desarrolla en la sociedad un gran movimiento creativo que cambia la forma de vida en las artes, la filosofía y la ciencia. En el marco de este movimiento, al Siglo XVI se le conoce como El Renacimiento, el Siglo XVII se le denomina El Barroco porque se utilizaba para subrayar el exceso de énfasis y abundancia de ornamentación en las artes y el Siglo XVIII de La Ilustración, que fue 
un período que resaltó la racionalidad clara y sobria, el poder de la razón humana, de la ciencia y el respeto hacia la humanidad.

El renacimiento representa la negación de la tradición filosófica medieval simbolizada en la escolástica. El renacimiento es un amplio movimiento cultural que se produjo en Europa Occidental. Sus principales exponentes se hallan en el campo de las artes plásticas, la literatura, la arquitectura, la escultura, en la política, en las ciencias, en la filosofía y en la religión. El núcleo de origen del renacimiento se da en Florencia (Italia), pero se extiende a la mayoría de los países de Europa occidental. El eje fundamental del renacimiento es el Humanismo, donde el hombre se concibe como centro de las artes y del pensamiento occidental, en oposición al conocimiento medieval que se movía en el ámbito de fe y el ocultismo.

Para la historia occidental, el siglo XV es el último siglo de la Edad Media y el primero de la Edad Moderna, es un siglo de transición, y se tiene como referencia de divisiónentreambossigloselaño1492(Descubrimiento de América) o el 1453 (toma de Constantinopla por los turcos). Lo perteneciente o relativo a este siglo suele denominarse como Quatrocento, porque es momento de la experimentación y de la reflexión teórica, y alcanza su plenitud durante los primeros años del siglo XVI que se denomina Cinquecento.

En el siglo XV es la decadencia de la edad media, de los burgos medievales surgen las ciudades típicas de la edad moderna, en estas ciudades viven los burgueses y a definirse el hombre burgués que se dedica al comercio, a la manufactura y a las finanzas. Este siglo XV marca el surgimiento de la edad moderna, pero no es un rompimiento de la edad media, es una transformación, es una continuidad.

"El absolutismo fue esencialmente eso: un aparato reorganizado y potenciado de dominación feudal, destinado a mantener a las masas campesinas en su posición social tradicional, a pesar y en contra de las mejoras que habían conquistado por medio de la amplia conmutación de las cargas. Dicho de otra forma, el Estado absolutista nunca fue un árbitro entre la aristocracia y la burguesía ni, mucho menos, un instrumento de la naciente burguesía contra la aristocracia: fue el nuevo caparazón político de una nobleza amenazada". (Anderson, 1989, p.136)

En el Siglo XV se realizan tres descubrimientos que fueron determinantes para los cambios en Europa: el uso de la pólvora en las armas, la brújula y la imprenta (1445). Estos descubrimientos provocaron cambios en el modo de hacer la guerra, en la comprensión y exploración del mundo y en la divulgación del conocimiento.

En el S. XVI Europa recibe el impacto de varios hechos que provocaron una serie de crisis de la conciencia europea: el descubrimiento de américa, la corrección de la imagen del mundo, la ruptura de la unidad del cristianismo, las reformas protestantes, el saqueo de Roma por las fuerzas imperiales de Carlos XV, y la teoría heliocéntrica del universo desarrollada por Copérnico.

Enesta era moderna las tres características que definen al hombre moderno son: ser individualista, laico (sin dejar de ser religioso) y racionalista. Ávila y Guillezeau (2009) señalan: “...una de las características más notables de la filosofía del Renacimiento ${ }^{2}$ es el antropocentrismo, lo que supone una valoración no sólo de la personalidad del ser humano, sino también de su individualidad. El Renacimiento supone pues el renacer del espíritu de libertad de un ser humano que se quiere inserto en la naturaleza y en la historia". (p. 124)

2 Las corrientes filosóficas en el renacimiento son múltiples y coexisten: (i) Platonismo; (ii) Aristotelismo averroista (un solo entendimiento) y Aristotelismo alejandrino (muchos entendimientos); (iii) Estoicismo; (iv) epicureísmo; (v) escepticismo; (vi) Naturalismo (Bruno, Telesio, Campanella); (vii). (Ávila y Guillezeau, 2009) 
Los humanistas consideraban al ser humano como centro y medida de todas las cosas (criterio de Protagoras), el orgullo por las realizaciones humanas, un ser libre y superior a otras criaturas. Esto se constituye como una diferencia con el pensamiento medieval que consideraba importante la vida ultraterrena.

El humanismo renacentista está comprometido, no solo con una renovación del individuo, sino con una revisión y reorganización de la vida social y política. Regresar a los orígenes significa valorar el mundo humano, su origen y condición humana, con libertad para decidir y opinar. Por ello, la gran importancia que se le imprime al pensamiento precristiano, al retorno a una comunidad histórica determinada, ya sea pueblo o nación y a su concepción de la antigua Grecia y la antigua Roma.

Echandi (2007) considera: "Los humanistas quisieron dar respuesta a los interrogantes del momento y para ello recurrieron tanto al cristianismo como a la filosofía grecolatina, creando así un sistema intelectual caracterizado por la supremacía del hombre sobre la naturaleza y el rechazo de las estructuras mentales impuestas por la religión medieval. La intención del humanismo era desarrollar en el hombre el espíritu crítico y la plena confianza en sus propias posibilidades, rasgos que le habían sido vetados durante la época medieval" (p.3)

En el renacimiento los humanistas cristianos tienen una gran influencia en el pensamiento político, principalmente: Erasmo de Róterdam y Tomás Moro.

Erasmo de Róterdam (1466-1536), a través de su obra ${ }^{3}$ denuncia la corrupción de las jerarquías eclesiásticas

3 Entre las principales obras de Erasmo de Róterdam están: Adagios (primera edición en 1500; edición corregida y aumentada por el autor en $1508,1518,1520,1523,1526,1528,1533$ y 1536), Manual del caballero cristiano (1503), Sobre el método de estudio (1511), Elogio de la locura (1511), Educación del príncipe cristiano (1516) dedicada a Carlos V y Colloquia (1517), con sucesivas ediciones corregidas y aumentadas por el autor en $1519,1522,1526,1530$. y se pronuncia a favor de un cristianismo renovado por la acción del Espíritu presente en el corazón de cada persona. El erasmismo como movimiento de carácter religioso, tuvo gran influencia en España en la segunda mitad del siglo XVI e incluso hasta bien entrado el siglo XVII, tuvo como fin la renovación de una espiritualidad que había caído muy bajo en los últimos siglos de la Edad media (Romero, 1994)

Las reflexiones de Erasmo sobre el Estado y la sociedad son opuestas al enfoque de Maquiavelo, dado que son los imperativos morales y religiosos los que definen las reglas de acción en la política. Por ejemplo, en su obra el elogio de la locura (1511) se burla de la falsa religiosidad y de la vida cortesana, del despotismo, de la guerra, de todo lo que deshonra la rectitud, la sinceridad, la tolerancia, el verdadero amor a Dios y a las personas.

He aquí un pequeño párrafo de la obra de El elogio de la locura: "Decía que la Fortuna prefiere a los insensatos, atrevidos, temerarios, aquellos que dicen como César al pasar el Rubicón: La suerte está echada. La prudencia hace a los hombres tímidos. Así vemos ordinariamente a tanto sabio sumido en la pobreza, el hambre y el dolor, vivir oscuramente, despreciado y detestado por el mundo. Los locos por el contrario, nadan en la opulencia, gobiernan imperios, en una palabra, gozan de una suerte más feliz y floreciente. En efecto, si cifráis la felicidad en complacer a vuestros soberanos y ser admitidos entre el brillante grupo de sus cortesanos, ¿de qué os sirve la sabiduría? Todos estos dioses de la tierra la detestan y no la admiten entre ellos" (Erasmo de Róterdam, p. 56)

Además, Erasmo considera que es preferible la elección del soberano a designarlo por herencia y es partidario de un tipo mixto de gobierno, combinando los tres regímenes políticos: democracia, aristocracia y monarquía. Sin embargo, su principal preocupación no fue el tipo de gobierno sino el espíritu y el corazón de los gobernantes. 
La influencia de Erasmo se basa en sus ideas pacifistas y la crítica constante a la guerra. Erasmo es considerado como el primer teorizador literario del pacifismo (Zweig, 1944), destacando el humanismo, el respeto a la diversidad, la libertad de pensamiento y la justicia como supremo ideal común a la humanidad.

Una de las obras más influyentes en el Eramismo fue la Educación del Príncipe Cristiano (1516) donde afirma que los gobernantes cristianos no sólo tienen que dominar los asuntos públicos, sino también deben ser honrados de acuerdo con los valores de una vida humana y cristiana (Ando, 1997, p.62).

Erasmo más que un filósofo fue un filólogo. "Erasmo intentó renovar la conciencia cristiana del pueblo dentro de la iglesia romana, retornando no sólo a los autores grecorromanos, sino mucho más al Nuevo Testamento y a los Santos Padres. Esta idea coincidía con el ideal de los humanistas, como los hermanos Vergara (Francisco y Juan) y el editor Miguel de Eguía, de la Universidad de Alcalá, establecida por Cisneros con dos objetivos primordiales: la instalación de un organismo completo de enseñanza eclesiástica; y la creación de la academia de estudios lingüísticos, como el griego, el hebreo, el árabe y el siríaco. El resultado más fructuoso del movimiento humanista alcalaíno fue la Biblia Poliglota Complutense, auténtico fruto del humanismo cristiano, cuyo lema era cum elegantia litterarum pietatis christiana copulare (Unir la piedad cristiana con la elegancia de las letras). (Ando, 1997, p. 61-62)

El Eramismo en España en el Siglo XVI fue un movimiento de carácter religioso, su significación abarcó la política, sociedad y cultura, porque influyó en las costumbres y ambiente moral de la época. E elemento central en la política en el humanismo es el principio de justicia y libertad.

Otra gran influencia en el humanismo cristiano fue Thomas Moro (1478-1535), se destaca con su obra
Utopía (1516) donde escribe sobre la organización de una sociedad utópica ubicada en una isla y los problemas sociales de la humanidad.

Ávila y Guillezeau (2009) señalan: "La Utopía de Tomás Moro, aun conteniendo aspectos ilustrados y prácticos, es ante todo idealización de las sociedades comunitarias del pasado y, en algunos aspectos, se opone al avance de las fuerzas y tendencias que darán paso posteriormente a la modernidad, como la expansión del comercio y la separación de poderes, entre otras (...) propone un Estado Igualitario en donde no existe propiedad privada y los magistrados son elegidos por el pueblo. Este género utópico no es nuevo, ya Platón en La República había propuesto un modelo ideal de Estado" (p.155)

Sin embargo, el modelo ideal de Estado en Thomas Moro es diferente a Platón en su planteamiento básico (Watson, 1994, p. 199-200):

1. Los dos creían que el Estado debía desempeñar un papel predominante en la educación, pero mientras que Platón apenas se refiere al comunismo, para Moro es la base de la sociedad.

2. A Platón le interesaba principalmente la educación de las clases dirigentes, mientras que para Moro había que tener muy en cuenta a los productores, y especialmente a agricultores.

3. Mientras que Platón alentaba la guerra y admiraba las virtudes militares, Moro trató de defender los valores pacifistas.

4. Platón ignora en gran parte la vida familiar, mientras que para Moro la familia es la base de la sociedad

Esta obra tuvo influencia posteriormente en el denominado Socialismo Utópico o primer Socialismo, de ahí el nombre, y surgen como teorías contrarias al individualismo. Las ideas de Moro sobre el control del Estado y sobre la educación fueron reconocidas por los socialistas, y también por los liberales cuando propone un programa de estudios amplio y equilibrado. 
El Siglo XVIII ${ }^{4}$ o siglo de "La llustración" se desarrolla un idealismo que no se basaba en la religión, sino en la naturaleza del ser humano, y sobrepuso como instrumento "la razón" para la libertad de las supersticiones. Estos iluministas niegan el "Derecho Divino", atacaron las prácticas religiosas e influyen en la secularización de las costumbres. En este período se combinan el racionalismo y el naturalismo, se cree en la bondad de la naturaleza del ser humano y en el poder de las ciencias físicas y matemáticas.

En este siglo la concepción de la política estuvo influenciada por los ilustrados franceses como: Montisquieu, Voltaire y Rousseau. Estos escritores tuvieron una gran influencia en la Revolución Francesa porque se opusieron a la monarquía absoluta y a la monarquía de origen divino.

En el caso de Charles Louis Montesquieu (1689-1755) escribe muchas obras, pero la más conocida es el Espíritu de las leyes ${ }^{5}$, donde menciona la teoría sobre la división de poderes. En este escrito destaca el valor de la libertad y la forma de asegurarla, declara que el Estado es libre cuando el poder detiene al poder, y propone la división de poderes: legislativo, ejecutivo y judicial. También se refiere a los poderes intermedios entre el individuo y el estado, como son: la nobleza, los municipios, la iglesia, etc. Estos poderes son autónomos. Montesquieu afirma: El poder intermedio subordinado más natural es el de la nobleza. Esta forma parte, en cierto modo, de la esencia misma de la monarquía, cuya máxima fundamental es: «sin monarca no hay nobleza; sin nobleza no hay monarca»; pero puede haber un déspota" (1909, p.31)

4 El siglo XVIII se le llamó el "Siglo de las luces", o de la "Ilustración", se ubica entre el período de la revolución inglesa (1688) y la revolución francesa (1789.

5 Monstisquieu en la obra de El Espíritu de las Leyes tiene como referencia el sistema político de Inglaterra donde había monarquía (el rey al frente del poder ejecutivo), aristocracia (Cámara de Lores) y representación popular (Cámara de los Comunes).
François Marie Arouet, conocido como Voltaire (16941778), en su obra cartas filosóficas y diccionario filosófico, desarrolla el concepto de la tolerancia religiosa y libertad ideológica, acusa al cristianismo de ser culpable de la intolerancia, la injusticia y el fanatismo dogmático. Voltaire en su obra Diccionario Filosófico afirma: "Es obvio que de todas las religiones, la cristiana debía ser la más tolerante; lo malo es que, hasta hoy, quienes han profesado esa religión superaron en intolerancia a los demás hombres". (p.811)

Otro destacado iluminista es Jean Jacques Rousseau (1712-1778) gran influyente en las ideas políticas del Siglo XVIII y se considera el principal filósofo de la Revolución Francesa. Uno de sus principales escritos es el contrato social (1762), Ávila y Guillezeau (2009) consideran que los principales aportes de esta obra son: "En el plano político refiere la soberanía de la voluntad del pueblo; con relación al Poder, ubica a los soberanos como mandatarios del pueblo; y, en el contexto de sistema, afirma a la República como forma perfecta de gobierno. Así como la naturaleza da a cada hombre un poder absoluto sobre todos sus miembros, el pacto social da al cuerpo político un poder absoluto sobre todos los suyos" (p.172)

Las causas fundamentales del término del estado absolutista fue la crisis económica causada por los lujos de los monarcas, el crecimiento del estado, el mantenimiento de un gran ejército para enfrentar las guerras territoriales y la furia del pueblo. Para superar la crisis se recurre al aumento de los impuestos, exigir que la nobleza pague diezmo y se incrementa la explotación de los campesinos obligándolos a dar mayores contribuciones. En Francia, la revolución francesa en 1879 marca el final del absolutismo y el surgimiento de un nuevo régimen donde la burguesía se convirtió en la fuerza política dominante. 


\section{CONCLUSION}

La construcción del estado moderno significó para los países de Europa la transformación de una sociedad que había estado conformada por feudos dispersos en los territorios, hacia una autoridad monárquica apoyada por los burgueses para concentrar el poder y establecerse como un estado absolutista. Los pensadores y filósofos de la época sustentan y justifican el autoritarismo en las premisas teóricas del Derecho Divino de los Reyes que lo plantea como el poder que proviene de Dios hacia el monarca, por ser la persona más capacitada para dirigir el futuro de sus súbditos.

Aunque este tipo de estado ha sido fuertemente criticado, no se puede obviar el drástico cambio que significó en su época, no solamente desde el punto de vista de la estructura del poder o los estamentos sociales, sino también por los cambios en la política económica del estado enfocada en la acumulación de oro y plata, la apertura comercial, el crecimiento de las ciudades, el impulso de la navegación, las ventajas aduaneras, entre otros.

Así mismo, se destacan las contribuciones de grandes pensadores que sientan las bases de conceptos importantes para el desarrollo de la política en la edad moderna, tales como: virtud republicana, soberanía, estructura del estado, diplomacia y extraterritorialidad. Se destaca en este período el cambio de paradigma que se da en Europa, de la negación de la escolástica de la edad media, que significó la subordinación de la razón a la fe, y el oscurantismo y temor a Dios promovido por el clero, por una etapa donde la razón humana adquiere valor supremo, se promueve al ser humano por su inteligencia y valor superior. El antropocentrismo restaura la fe en el ser humano contemporáneo.
Este cambio de paradigma encarnó una nueva forma de pensar y de vivir, se trasciende del pesimismo y milenarismo medievales al optimismo del humanismo renacentista, lo que permitió un mayor crecimiento que se refleja en importantes descubrimientos, y el desarrollo de las artes, filosofía, arquitectura, y ciencia. De esta manera, el nuevo paradigma permitió redefinir y proponer nuevos enfoques políticos, tales como: la soberanía sustentada en el pueblo, el control y la división de poderes en el estado, la separación de la iglesia con el estado, el pacifismo, el respeto a la libertad, la libertad de pensamiento y el estado igualitario.

\section{BIBLIOGRAFÍA}

Ando, Shinjiro (1997). El Eramismo Español: Una tradición humanista Española. Cuadernos Canela Vol. XIX, pps 57-69. Consultado: (7 Junio, 2013). Disponible en: http://www.canela.org.es/ cuadernoscanela/canelapdf/cc9ando.pdf

Ávila, Nelson; Guillezeau, Patricia (2009). Poder, política, estado y democracia. Aproximación teórica y práctica desde la Era Presocrática hasta el Siglo XXI. Universidad del Zulia. Venezuela.

Bodin, Jean (1997). Los seis libros de la república. Selección, estudio preliminar y traducción de Pedro Bravo Gala. Editorial TECNOS. Tercera edición. Consultado: (3 Junio, 2013). Disponible en: http://es.scribd.com/doc/80709045/BodinoJean-Los-Seis-Libros-de-La-Republica

Borgucci, Emmanuel (2011). Vigencia de algunas de las ideas mercantilistas de Thomas Mun. Revista de Ciencias Sociales (Ve), vol. XVII, núm. 2, abril-junio, pp. 359-374, Universidad del Zulia, Venezuela. Consultado: (6 Junio, 2013). Disponible en: www.redalyc.org/articulo.oa? id=28022757014

De Rótterdam, Erasmo (Sf). Elogio a la locura. Edición digital de Escuela de Filosofía. Universidad ARCIS. Consultado: (7 Junio, 2013). Disponible en: http:// www.philosophia.cl/biblioteca/erasmo/Elogio $\% 20$ de\%20la\%20locura.pdf 
Echandi G., Marcela (2007). El ejercicio del poder político en el renacimiento a través de El Príncipe. Revista de Estudios. No.20, anual. Escuela de estudios generales. Universidad de Costa Rica. Costa Rica. Consultado: (5 Junio, 2013). Disponible en: http://www.estudiosgenerales.ucr. ac.cr/estudios/no20/papers/iisec3.html

Fabal, Gustavo. (1973). Pensamiento social desde el medioevo hasta el siglo XIX. Versión de la editorial de Ciencias Sociales del I.L.C. La Habana, Cuba.

Fazio, Mariano (2006). Historia de las ideas contemporáneas. Una lectura del proceso de secularización. 1ra. Edición española.

Hobbes, Thomas (1651). Fragmentos de Leviatán. Consultado: (5 Junio, 2013). Disponible en: http://www.teoriasdelaamistad.com.ar/pagina5/ Unidad2/1Hobbes.pdf

Jiménez Castaño, David (2008). El origen medieval del absolutismo político hobbesiano: del dios omnipotente de Guillermo de Ockham al soberano absoluto de Thomas Hobbes. Miscelánea Medieval Murciana, XXXII; pp. 91-102. Consultado: (30 Abril, 2013). Disponible en: http://revistas.um.es/ mimemur/article/view/49301

Pastor Pérez, Miguel A. (1994). El arte de la simulación. Estudio sobre ciencia y política en Nicolás Maquiavelo. ORP, Colección Raigal No. 2, Sevilla, España. pp. 198. Citado en Cuadernos sobre Vico 5/6, 1995-96, pp. 345-350. Consultado: (5 Junio, 2013). Disponible en: http://institucional.us.es/ cuadernosvico/uploads/n5y6/savilla3.pdf

Perry, Anderson (1987). El Estado absolutista. Capítulo I. El Estado absolutista en Occidente. Siglo XX editores. México.

Romano, Ruggiero; Tenenti, Alberto (1986). Los fundamentos del mundo moderno: edad media tardía, reforma y renacimiento. Historia universal siglo XXI. Volumen 12. Siglo XXI de España Editores S.A. 18va edición en castellano. España. Romero Tabares, María Isabel (1994). El pensamiento Erasmista. Su aportación a la cultura y sociedad españolas del siglo XVI. Cuadernos sobre
Vico No.4. pp. 149-166. Consultado: (7 Junio, 2013). Disponible en: http://institucional.us.es/ cuadernosvico/uploads/n4/romero.pdf

Montesquieu (1909). El espíritu de las leyes. Vertido al castellano con notas y observaciones por Sirio García del Mazo. Biblioteca de Derecho y de Ciencias Sociales. Librería general de Victoriano Suarez. Madrid, España. Consultado: (18 Junio, 2013). Disponible en: http://fama2.us.es/fde/ ocr/2006/espirituDeLasLeyesT1.pdf

Voltaire (Sf). Cartas filosóficas. Consultado: (18 Junio, 2013). Disponible en: http://www.bsolot.info/ wp-content/uploads/2011/02/Voltaire-Cartas_ filosoficas.pdf

Voltaire (Sf). Diccionario filosófico. Consultado: (18 Junio, 2013). Disponible en: http://biblio3.url.edu. gt/Libros/dic_fi.pdf

Watson, Keith (1994). Tomas Moro (1478-1535). Perspectivas: revista trimestral de educación comparada (París, UNESCO: Oficina Internacional de Educación), vol. XXIV, nos 1-2, págs. 181-199. Consultado: (7 Junio, 2013). Disponible en: http:// www.ibe.unesco.org/publications/ThinkersPdf/ moros.PDF

Zweig, Stefan (1944). Erasmo de Rotterdam, triunfo y tragedia. Consultado: (7 Junio, 2013). Disponible en: http://www.remq.edu.ec/libros/ Stefan $\% 20 Z$ weig $\% 20$ - \%20Erasmo\%20de\%20 Rotterdam,\%20Triunfo\%20y\%20Tragedia.pdf 